\title{
The Efficacy of Bioabsorbable Mesh in Craniofacial Trauma Surgery
}

\author{
Won Chul Choi', \\ Hyun Gon Choi', \\ Jee Nam Kim ${ }^{1}$, \\ Myung Cheol Lee ${ }^{1}$, \\ Dong Hyeok Shin', \\ Soon Heum Kim², \\ Cheol Keun Kim², \\ Dong $\ln \mathrm{JO}^{2}$
}

${ }^{1}$ Department of Plastic and Reconstructive Surgery, Konkuk University Medical Center, Konkuk University School of Medicine, Seoul; ${ }^{2}$ Department of Plastic and Reconstructive Surgery, Konkuk University Chungju Hospital, Konkuk University School of Medicine, Chungju, Korea

No potential conflict of interest relevant to this article was reported.
Background: The ultimate goal of craniofacial reconstructive surgery is to achieve the most complete restoration of facial functions. A bioabsorbable fixation system which does not need secondary operation for implant removal has been developed in the last decade. The purpose of this study is to share the experience of authors and to demonstrate the efficacy of bioabsorbable mesh in a variety of craniofacial trauma operations.

Methods: Between October 2008 and February 2015, bioabsorbable meshes were used to reconstruct various types of craniofacial bone fractures in 611 patients. Any displaced bone fragments were detached from the fracture site and fixed to the mesh. The resulting bone-mesh complex was designed and molded into an appropriate shape by the immersion in warm saline. The mesh was molded once again under simultaneous warm saline irrigation and suction.

Results: In all patients, contour deformities were restored completely, and bone segments were fixed properly. The authors found that the bioabsorbable mesh provided rigid fixation without any evidence of integrity loss on postoperative computed tomography scans.

Conclusion: Because bioabsorbable meshes are more flexible than bioabsorbable plates, they can be molded and could easily reconstruct the facial bone in three dimensions. Additionally, it is easy to attach bone fragments to the mesh. Bioabsorbable mesh and screws is effective and can be easily applied for fixation in various craniofacial trauma reconstructive scenarios.

Keywords: Absorbable implants /Fracture fixation, internal/ Orbital fractures / Zygomatic fractures / Maxillary fractures

\section{INTRODUCTION}

The main role of craniofacial skeleton is to support and protect the important soft-tissue organs. Craniofacial bone fractures and congenital anomalies can cause functional and aesthetic problems. In severe cases, disruptions in the craniofacial skeleton can affect breathing, speech, sight, and the ability to swallow. Craniofacial reconstructive surgery is performed following facial trauma

\footnotetext{
Correspondence: Hyun Gon Choi

Department of Plastic and Reconstructive Surgery, Konkuk University Medical Center, Konkuk University School of Medicine, 120-1 Neungdong-ro, Gwangjin-gu, Seoul 05030, Korea

E-mail:20040059@kuh.ac.kr

*This article was presented at the Research and Reconstructive Forum on May, 14-15, 2015.

Received May 24, 2016 / Revised July 20, 2016 / Accepted July 26, 2016
}

and for treating congenital anomalies in order to achieve the most complete restoration of facial functions.

Adequate reduction and durable fixation are the most important goals in facial bone reconstruction. Titanium plates and screws has been the golden standard for fixation in craniofacial reconstructive surgery [1-4]. During the last few decades, significant developments have taken place in the management and the materials used for craniofacial reconstruction.

Materials used for fixation of the craniofacial bone can be categorized into metallic or bioabsorbable materials. Clinical knowledge about the use of bioabsorbable materials has allowed application of these materials in orthgnathic and facial trauma surgeries [5-7]. The most relevant advantage is the absence of the need for a 
second-stage operation to remove implants [8]

Bioabsorbable materials for craniofacial surgery can be divided into bioabsorbable plate or bioabsorbable mesh. Bioabsorbable plate has been accepted internationally. The advantages of bioabsorbable meshes over the plates are the ease in designing and shaping the implant such that the prepared material matches the curvature of the facial skeleton.

In this study, we report the use of bioabsorbable mesh in various craniofacial trauma reconstructions. The purpose of this study is to focus on the outcome and efficacy of bioabsorbable mesh in craniofacial trauma surgery.

\section{METHODS}

\section{Patients}

The study includes a total of 611 patients in whom a bioabsorbable mesh was for craniofacial reconstruction at our institution between October 2008 and February 2015. Medical records were re- viewed for demographic information, injury characteristics, operative details, and clinical outcomes. To ensure an accurate diagnosis, the patients routinely underwent preoperative axial, coronal, sagittal plane view, and 3-dimensional computed tomography $(\mathrm{CT})$ imaging, in addition to plain radiographs and physical examination.

\section{Surgical techniques}

Each fracture site was exposed with periosteal dissection. We designed a bioabsorbable mesh (MacroPore, $30 \times 36 \mathrm{~mm}$ or $50 \times 50$ mm, $0.5 \mathrm{~m}$ in thickness; Medtronic, Minneapolis, MN, USA) and immersed it in heating bath (saline water at $55^{\circ} \mathrm{C}$ ) to mold the mesh to the contour of each bone lesion. Displaced bone fragments were removed from the fracture site and were re-aligned on to the mesh using absorbable screws. This bioabsorbable mesh was then internally fixated to the intact adjacent bone also using several absorbable screws. The mesh was molded once again according to the facial bone curvature, under warm saline irrigation (Figs. 1, 2).

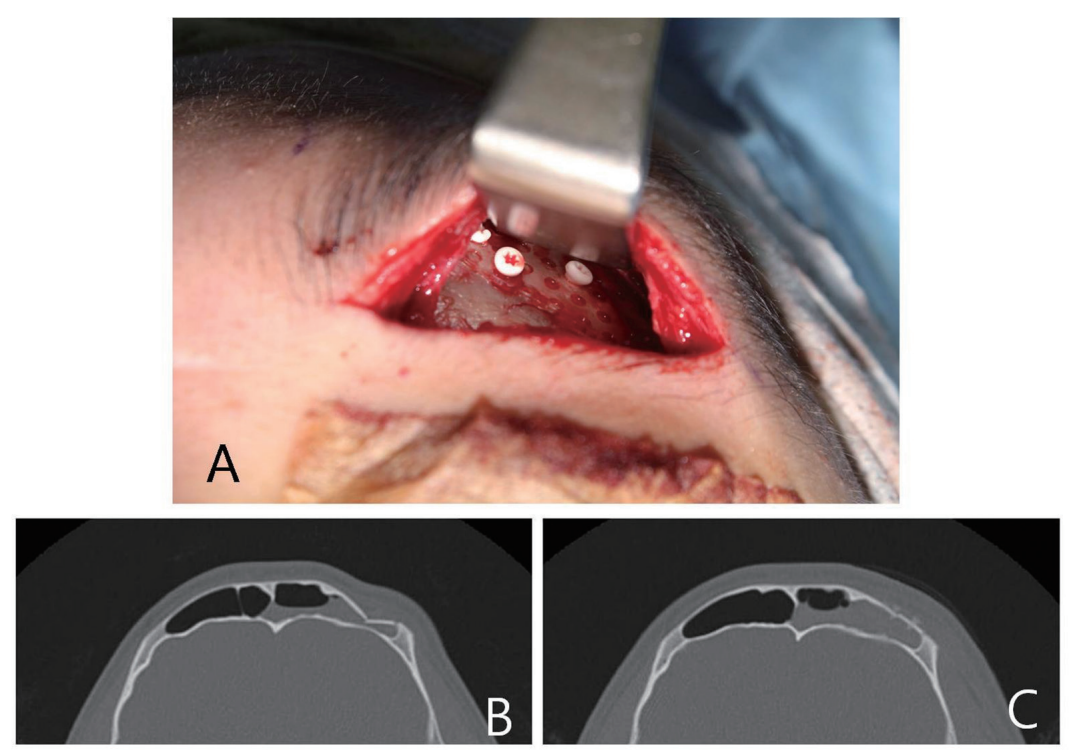

Fig. 1. Fracture reduction and bioabsorbable mesh fixation. This 20 -year-old male patient presented with an anterior wall fracture of the frontal sinus after being hit by a baseball. A 4-cm incision was made in the subbrow area to access the frontal sinus. The fracture site was completely exposed by periosteal stripping. Intraoperative findings confirmed the presence of a step-off deformity. A bioabsorbable mesh was cut to the appropriate size, and then soaked in saline bath at $55^{\circ} \mathrm{C}$ to be molded to the curved shape of frontal sinus. Then, depressed bone fragments $(4$ $\mathrm{cm} \times 3 \mathrm{~cm}$, when aligned together) were detached from the fracture site and attached to the bioabsorbable mesh. (A) The mesh with attached bone fragments was fixed onto the intact surrounding bone. (B) Preoperative computed tomographic scan shows a depressed fracture of the left anterior table of the frontal sinus. (C) Postoperative computed tomography images demonstrates a near-normal contour of the frontal sinus. Preoperatively, the patient had been complaining of forehead paresthesia, which was resolved with the operation. 

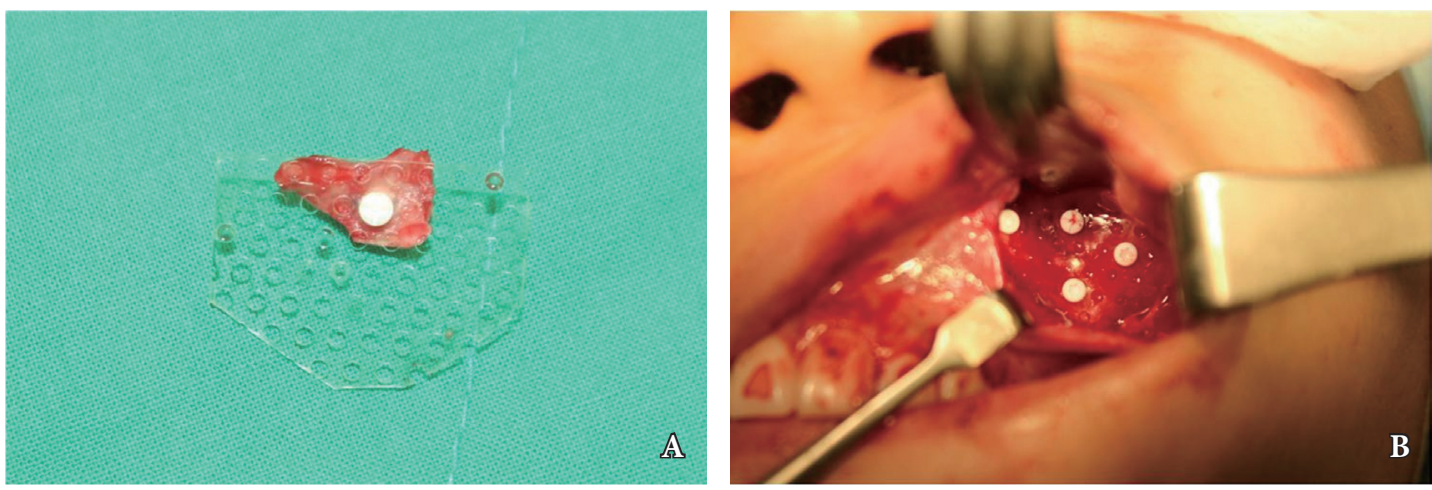

Fig. 2. Internal fixation of the bioabsorbable mesh. The patient was a 25 -year-old woman presenting with a left zygomaticomaxillary complex fracture. A $5 \mathrm{~cm}$ intraoral incision was made on the upper gingivobuccal sulcus. The periosteum was dissected in order to completely expose the fracture site. The loose bone fragments were detached from the anterior wall of the maxillary sinus. The bioabsorbable mesh was designed in the appropriate size and shape so that it would not compress the infraorbital nerve. The mesh was soaked in warm saline and molded to the curvature of maxillary sinus. (A) A detached bone fragment was attached to the mesh by a bioabsorbable screw. (B) The bone-and-mesh complex was subsequently fixed to the intact bone. The fixed mesh was irrigated with $55^{\circ} \mathrm{C}$ saline solution to allow for firm contact between the mesh and the facial bone, which was simultaneously carried out with suction to avoid infraorbital nerve injury.

\section{RESULT}

The study identified 501 men (82.0\%) and 110 women (18.0\%). The mean age was 40.5 years (range, 7 to 94 years). The fracture sites were blow-out fracture in 392 cases, zygomaticomaxillary complex fracture in 34 cases, nasal septum fracture in 16 cases, frontal bone in 14 cases, and complex facial bone fracture (more than two fracture sites) in 155 cases (Table 1). Injury mechanism included physical altercation, automobile collisions, motorcycle collisions, vehicle-vs-pedestrian collisions, work-related accidents, sports-related injuries, slipping, and fall (Table 2). The mean follow-up duration was 11.4 weeks (range, 1 week to 3 years).

Displaced bone segments were reduced and fixed properly in all patients. The authors found that bioabsorbable meshes provided rigid fixation without any evidence of loss of integrity on postoperative CT scans.

Overall, preoperative symptoms were observed in 335 patients (54.7\%), including numbness in 266 cases (43.5\%), extraoccular movement (EOM), discomfort in 159 cases (26.0\%), diplopia in 93 cases (15.2\%), enophthalmos in 3 cases (0.5\%), blurry vision in 7 cases (1.1\%), and septal deviation in 16 cases (2.6\%). Postoperative complications were observed in 46 patients (13.7\%), including numbness in 31 cases (5.1\%), EOM discomfort in 7 cases (1.1\%), diplopia in 3 cases $(0.5 \%)$, enophthalmos in 1 case $(0.2 \%)$, ectropi- on in 3 cases $(0.5 \%)$, and infection in 2 case $(0.3 \%)$ (Table 3 ).

There were no cases of malunion, nonunion, or contour abnormalities. None of the patients experienced any reaction to the mesh or screws, and no implant became exposed.

Table 1. Fracture site

\begin{tabular}{lc} 
Fracture site & No. (\%) \\
\hline Blow out fracture & $392(64.1)$ \\
\hline Zygomaticomaxillary & $34(5.6)$ \\
\hline Nasal septum & $16(2.6)$ \\
\hline Frontal bone & $14(2.3)$ \\
\hline Complex facial bone & $155(25.4)$ \\
\hline
\end{tabular}

Table 2. Clinical data by injury mechanism

\begin{tabular}{lccc}
\multirow{2}{*}{ Etiology } & \multicolumn{2}{c}{ Sex } & Total (\%) \\
\cline { 2 - 3 } Altercation & Male & Female & \\
Car & 145 & 11 & $156(25.7)$ \\
\hline Motorcycle & 19 & 16 & $35(5.7)$ \\
\hline Bicycle & 43 & 5 & $48(7.8)$ \\
\hline Vehicle- vs. -Pedestrian & 28 & 5 & $33(5.4)$ \\
\hline Work-related accident & 22 & 11 & $33(5.4)$ \\
\hline Sport-related injury & 4 & - & $4(0.7)$ \\
Slipping & 44 & 3 & $47(7.7)$ \\
\hline Fall & 69 & 27 & $96(15.7)$ \\
Miscellaneous injuries & 32 & 11 & $43(7.0)$ \\
\hline Unknown & 81 & 21 & $102(16.7)$ \\
\hline Total & 14 & 0 & $14(2.2)$ \\
\hline
\end{tabular}


Table 3. Postoperative complications

\begin{tabular}{lc} 
Complications & Number (\%) \\
\hline Numbness & $31(5.1)$ \\
\hline EOM discomfort & $7(1.1)$ \\
\hline Diplopia & $3(0.5)$ \\
\hline Enophthalmos & $1(0.2)$ \\
\hline Infection & $2(0.3)$ \\
\hline Ectropion & $3(0.5)$ \\
\hline
\end{tabular}

EOM, extraoccular movement.

\section{DISCUSSION}

The use of titanium plates and screws to achieve stable facial bone fixation has been well documented. These materials have become the standard hardware used for fixation of craniofacial bone fractures. However, there are disadvantages to using titanium plates and screws [9,10]. Orringer et al. [11] identified the reasons for implant removal in craniofacial surgical patients and found that palpable implants were the most common cause of removal, in addition to infection, pain, wound dehiscence, thermal sensitivity, plate migration, and loosening of plates and screws [12]. In our study, signs of postoperative infection were present in 2 patients. However, postoperative IV antibiotics were adequate in controlling initial nidus and obviated the need for mesh removal.

Despite these disadvantages, rigid fixation using titanium plates and screws was relatively successful in the adult population. Therefore, surgeons extended its application to craniofacial reconstructive surgery in children [13]. But there are different considerations for the pediatric craniofacial reconstructive surgery compared with the adult reconstructive surgery. These include tremendously accelerated ability to heal and being in the midst of bone growth. Lin et al. found that rigid fixation might affect the growth of surrounding bones and result in craniofacial deformities [14]. Because of these negative results after the use of rigid fixation in pediatric patients, fixation with bioabsorbable materials should be considered the standard of care for craniofacial bone fixation in children [15-17].

The bioabsorbable mesh used in our study is composed of 70\% poly L-lactic acid and 30\% poly D, L-lactic acid in combination. This polymer provides optimal strength and resorption time.
Rehm et al. [18] reported that this combination of polymers retains approximately $68 \%$ of its initial strength after 8 weeks, approximately $30 \%$ its initial strength after 6 months, and is absorbed completely within 24 months. The material is biocompatible and is suitable for use in craniofacial reconstructive surgery [8]. Although biomechanically inferior to titanium plate and screws, the bioabsorbable plate and screw appear to provide equivalent results when compared to metal fixation systems in an animal model [8].

Bioabsorbable mesh was originally used for orbital wall fractures. Baek et al. [19] reported that both bioabsorbable and titanium meshes showed good results without significant differences in long term follow-up. Tabrizi et al. [20] evaluated orbital floor reconstruction in 101 patients using autologous bone and various alloplastic materials (Medpor, Medpor Titan, titanium mesh, and resorbable plates). The authors concluded that these alloplastic materials provided structural support and could be successfully used in large orbital floor defects. These bioabsorbable meshes and screws commonly used for blowout fracture are inappropriate for frontal bone and zygomaticomaxillary complex fractures because these bones tend to fracture into multiple small fragments. Kim et al. [21] performed successful treatment of frontal sinus fracture using the bioabsorbable mesh. The method involved use of mesh applied in surgery for fracture. Detached bone fragments were attached to the prepared bioabsorbable mesh. The mesh was molded in heating bath, and while fixing the bonemesh complex to the remainder of zygomaticomaxillary bone, the mesh was molded once again by warm saline irrigation. By performing irrigation and suction at the same time, we could avoid thermal injury to the soft tissue, including the nerve and artery.

Nasal bone fracture is one of the most common facial bone fractures, and it is frequently accompanied by septal fracture. Kim et al. [10] reported that $46.9 \%$ of nasal bone fractures are accompanied by septal fractures. For nasal bone fractures with accompanying septal fracture, we approached the septum though an inverted L-shaped incision at the mucocutaneous junction. We straightened the fractured cartilage and inserted a $2 \times 3 \mathrm{~cm}$ pentagonal bioabsorbable mesh. Then, the mesh was fixed as an internal splint between the perichondrium and the cartilage. In or- 
der to keep the bioabsorbable mesh in the desired place, a silicone sheet was fixed for seven days. The nasal packing was removed five days after the operation, and afterwards, the mesh functioned as a buttress for the septum.

Bone fragment reduction with bioabsorbable mesh and screws is relatively easy because it allow fixation of small bone fragments away from the fractured site. Also, the bioabsorbable mesh is thin and convenient for designing and trimming with scissors. Placing the fixation material on the outer surface of craniofacial bone can result in suboptimal cosmetic outcome, as the plates and screws can be palpable. However, as time passes, the fixation material placed under the skin degrades naturally and is no longer palpable. This phenomenon increases patient satisfaction for the absorbable system. In addition, holes on the surface of the bioabsorbable mesh are the grounds for the close contact between the soft tissue and bone fragments, which leads to successful healing within the fracture site [22].

For several years, we have been using the bioabsorbable mesh for treating facial bone fractures. Based on this experience, we suggest that bioabsorbable mesh can be easily applied in a variety of craniofacial trauma reconstructions.

\section{REFERENCES}

1. Assael LA. Considerations in rigid internal fixation of midface trauma. Oral Maxillofac Surg Clin North Am 1990;2:103-19.

2. Spiessl B. Internal fixation of the mandible: a manual of $\mathrm{AO} / \mathrm{ASIF}$ principles. Berlin: Springer Berlin Heidelberg; 1989.

3. Yaremchuk MJ, Gruss JS, Manson PN. Rigid fixation of the craniomaxillofacial skeleton. Boston: Butterworth-Heinemann; 1992.

4. Prein J, Arbeitsgemeinschaft für Osteosynthesefragen. Manual of internal fixation in the cranio-facial skeleton: techniques recommended by the AO/ASIF-Maxillofacial Group. New York: Springer; 1998.

5. Goldstein JA, Quereshy FA, Cohen AR. Early experience with biodegradable fixation for congenital pediatric craniofacial surgery. J Craniofac Surg 1997;8:110-5

6. Habal MB. Absorbable, invisible, and flexible plating system for the craniofacial skeleton. J Craniofac Surg 1997;8:121-6.

7. Kumar AV, Staffenberg DA, Petronio JA, Wood RJ. Bioabsorbable plates and screws in pediatric craniofacial surgery: a review of 22 cases.
J Craniofac Surg 1997;8:97-9.

8. Suuronen R, Pohjonen T, Vasenius J, Vainionpaa S. Comparison of absorbable self-reinforced multilayer poly-l-lactide and metallic plates for the fixation of mandibular body osteotomies: an experimental study in sheep. J Oral Maxillofac Surg 1992;50:255-62.

9. Francel TJ, Birely BC, Ringelman PR, Manson PN. The fate of plates and screws after facial fracture reconstruction. Plast Reconstr Surg 1992;90:568-73.

10. Kim JH, Shin DW, Choi TH, Son DG, Han KH. The importance of septoplasty in the treatment of nasal bone and grade i septal fracture: estimation with acoustic rhinometry. J Korean Soc Plast Reconstr Surg 2010;37:626-32.

11. Orringer JS, Barcelona V, Buchman SR. Reasons for removal of rigid internal fixation devices in craniofacial surgery. J Craniofac Surg 1998;9:40-4.

12. Schmidt BL, Perrott DH, Mahan D, Kearns G. The removal of plates and screws after Le Fort I osteotomy. J Oral Maxillofac Surg 1998;56:184-8

13. Beals SP, Munro IR. The use of miniplates in craniomaxillofacial surgery. Plast Reconstr Surg 1987;79:33-8.

14. Lin KY, Bartlett SP, Yaremchuk MJ, Grossman RF, Udupa JK, Whitaker LA. An experimental study on the effect of rigid fixation on the developing craniofacial skeleton. Plast Reconstr Surg 1991;87:229-35.

15. Yaremchuk MJ, Fiala TG, Barker F, Ragland R. The effects of rigid fixation on craniofacial growth of rhesus monkeys. Plast Reconstr Surg 1994:93:1-10

16. Fearon JA, Munro IR, Bruce DA. Observations on the use of rigid fixation for craniofacial deformities in infants and young children. Plast Reconstr Surg 1995;95:634-7.

17. Yu JC, Bartlett SP, Goldberg DS, Gannon F, Hunter J, Habecker P, et al. An experimental study of the effects of craniofacial growth on the long-term positional stability of microfixation. J Craniofac Surg 1996;7:64-8.

18. Rehm KE, Helling HJ, Claes L. Report of the Biodegradable Implants Study Group. Aktuelle Traumatol 1994;24:70-3.

19. Baek WI, Kim HK, Kim WS, Bae TH. Comparison of absorbable mesh plate versus titanium-dynamic mesh plate in reconstruction of blow-out fracture: an analysis of long-term outcomes. Arch Plast Surg 2014;41:355-61.

20. Tabrizi R, Ozkan TB, Mohammadinejad C, Minaee N. Orbital floor reconstruction. J Craniofac Surg 2010;21:1142-6.

21. Kim CH, Kim DH, Kim DH, Song SY. Treatment of frontal sinus fracture using bioabsorbable mesh plates. J Craniofac Surg 2012;23: 549-51.

22. Shin DH, Kim DJ, Kim SY, Hwang EA, Choi HG, Kim SH, et al. Rigid fixation using bioabsorbable mesh and screws in facial bone fracture. J Korean Soc Plast Reconstr Surg 2010;37:717-20. 